\title{
Intestinal colonization of infants with multidrug resistant Pseudomonas aeruginos in tertiary care center in Jordan
}

Noor Issam Shishtawi ${ }^{1}$, Manar Al-lawama², Asem A. Shehabi ${ }^{1}$

1 Department of Pathology-Microbiology and Forensic Medicine, The University of Jordan, Amman, Jordan

2 Department of pediatrics, Jordan University Hospital, Amman, Jordan.

Contact information:

Professor Asem A. Shehabi.

"] asashehabi2@gmail.com

Methods: A total of 302 feces samples were obtained randamely from neonates and infants admitted to Pediatric Clinic and the Neonate Intensive Care Unit (NICU)/Jordan University Hospital (JUH), over a 9-month period of 2016-2017. Fecal samples were cultured for $P$. aeruginosa and their growth was identified and tested using microbiological and antibiotic susceptibility methods. Additionly, virulence factors, antimicrobial resistance genes and genotypes were detected using Polymerase Chain Reaction (PCR).

Results: A total of $16 / 302$ (5.3\%) of $P$. aeruginosa isolates were recovered from feces samples of only hospitalized infants. Antimicrobial susceptibility of the isolates ranged between the lowest $18.7 \%$ to meropenem and highest of $87.5 \%$ to azetreonam among 9 tested drugs. The percentage of specific genes of ESBLS and MBLs in $16 P$. aeruginosa isolates were the following: blaOXA-50, blaTEM, blaCTX$M$, blaVIM, blaKPC, blaSHV, blaGES, and blaVEB were detected at the rate of $13(81.2 \%), 13(81.2 \%), 12(75 \%), 12(75 \%), 11(68.7 \%), 10$ $(62.5 \%), 2(12.5), 1(6.2 \%)$, respectively. The percentage of the potential virulence genes in the same isolates were detected as follow: lasB, algD, toxA, exos and exoU at the rate of $100 \%, 87.5 \%, 81.2 \%$, 
$81.2 \%, 31.2 \%$, respectively. All $P$. aeruginosa isolates observed to develop beta-hemolysis on both human and sheep blood agar, and to produce either pyoverdin (56.3\%) or pyocyanin (43.7\%).

Conclusions: The present study demonstrates high occurrence of multidrug resistant $P$. aeruginosa isolates from only hospitalized infant feces which also carried high rates of important genes of ESBLS and $M B L s$ and potential virulence factors.

\section{Keywords}

Pseudomonas aeruginos; Multidrug resistance; Intestinal tract; Infant;

Virulence factors.

\section{Introduction}

Pseudomonas aeruginosa is a major cause of nosocomial infections in children and adults, and its responsible for about $10 \%$ of all hospital-acquired infections worldwide [1, 2].

$P$. aeruginosa causes severe infections especially in immune-compromised patients, and it continues to pose a therapeutic challenge resulting in high rate of morbidity and mortality due to development of drug resistance during antibiotic treatment of patients [3-4].

$P$. aeruginosa infections are becoming more difficult to treat, and the number of multidrug drug resistant isolates from clinical and hospital environment sources is increasing worldwide including Arab Middle East countries [1, 5-7]. Recently, the most important issue is the emergence of carbapnemases in $P$. aeruginosa which considered as the last-line agents against Gram-negative bacteria infections [8].

$P$. aeruginosa infections are especially difficult to prevent and to treat because of its common occurrence in hospital environment and water sources, and for both intrinsic resistance to many antibiotics as well as rapid development of antibiotic resistance
[9-11]. These features facilitate $P$. aeruginosa infections to become a serious health care issue in hospitals worldwide [12].

$P$. aeruginosa is associated with presence and execration of large virulence factors that are involved in various stages of the infection process allowing the organism to colonize any part of the infected host. These virulence factors include flagellum, type IV pili, lipopolysaccharide, a type III secretion system, and alginate which are involved in the adhesion, motility and colonization [13-14]. In particular, $P$. aeruginosa is possessing cell-associated and extracellular virulence factors controlled by a complex regulatory circuit involving cell-to-cell signaling (quorum sensing) system, allowing hostpathogen interactions during infections [15]. The organism also releases several metabolites including mainly, exotoxins, exoproteases, heamolysins and pyocyanin or pyoverdin-fluorescein pigments. All these virulence factors are causing extensive tissue damage as well as facilitate bacterial multiplication and the spread in host tissues $[5,16]$.

The emergence of extended-spectrum- $\beta$ lactamases (ESBLs) and metallo- $\beta$-lactamases (MBLs) compromised the effect of most $\beta$-lactam antibio- 
tics including carbapenems which are the drug of choice for treatment of infections of Gram-negative ESBL-producers [17-18]. Reports of carbapenem resistant $P$. aeruginosa recovered from patients have been documented from different Arab regions, including Jordan, Syria, Egypt, Saudi Arabia, Kuwait and Lebanon [5, 19-23].

This study aims to investigate the distribution of most important types of ESBLs, MBLs, and potential virulence genes in $P$. aeruginosa isolates from feces of examined infants in a tertiary care center in Amman, Jordan by using culture and molecular PCR methods.

\section{Materials and Methods}

This prospective study was randamly conducted at Jordan University Hospital (JUH) neonatal unit and at outpatient pediatric clinic over the period from May 2016 to February 2017, only one sample was collected from each patient.

The study was approved by the IRB and ethical committee at JUH (2016/118). Informed consent was taken from parents before obtaining the fecal samples.

Neonates and infants up to one year old were included in the study. Neonates and infants with gastrointestinal anomalies and those whoes parents declined consent were excluded. Anal swabs were colleted by neonatal nurse or physician.

Medical charts of included infants were reviewed and their parents were interviewd using a structured data sheet. Demographic and clinical data in addition to current or recent antibiotics therapy within two weeks of the encounter were also documente.

\section{Bacterial standard strains}

The following bacterial standard strains were included as control: P. aeruginosa controls: ATCC 27853, ATCC 9027, and $P$. aeruginosa PAO1 strain had been used for quality control of antimicrobial susceptibili- ty test and PCR detection of $P$. aeruginosa strains, and controls (CL 120 \& CL 162, Universite' Libanaise, Tripoli, Libanon, Prof. Monzer Hamze) that were positive for IMP-1, VIM-2, K. pneumonia (ATCC BAA-1705) positive for blaKPC and E. coli (ATCC 51446) positive for blaCTX-M, and blaNDM-1).

\section{Culture, isolation, identification}

All fresh collected fecal samples had been diluted in $2 \mathrm{ml} \mathrm{NaCl}$-saline (0.9\%) and then inoculated onto Cetrimide Pseudomonas Selective Agar (Merck, Germany).

All suspected growth of $P$. aeruginosa was identified as $P$. aeruginosa according to the following characteristics: positive oxidase test, growth at 42 ${ }^{\circ} \mathrm{C}$, negative lactose and glucose fermentation in tube of Kligler iron agar. Five colonies of $P$. aeruginosa growth were subcultured into cetrimide agar to get pure culture of the organism and then a few colonies were inoculated and stored in cryotubes containing brain-heart infusion broth with $20 \%$ glycerol at $-70{ }^{\circ} \mathrm{C}$ for further investigation and confirmation by $P C R$.

\section{Antimicrobial susceptibility test using disc diffusion method}

Antimicrobial susceptibility test using disc diffusion method was performed according to the recommendation of the Clinical Laboratory and Standards Institute (CLSI, 2015) [24].

\section{Minimum inhibitory concentration (MIC) using E-test}

All isolates of $P$. aeruginosa which were MDR to three or more antibiotic classes have their MICs measured by E-test for ceftazidime, amikacin, colistin, and imipenem, and their results were interpreted according to CLSI, 2015 [24].

\section{DNA extraction and PCR procedure}

The bacterial DNA was extracted using the Wizard genomic DNA Purification Kit 
(Promega, USA) according to manufactures instructions. Two PCR assays were performed; one is specific for the genus Pseudomonas, while the other is specific for $P$. aeruginosa. Two pairs of primers were used for each assay based on 16 ribosomal DNA ( $r D N A$ ) sequence. A positive control of $P$. aeruginosa ATCC 27853 and ATCC 9027 were used for the identification of the specific sequences.

\section{Plasmid extraction}

The bacterial plasmid was extracted using the EZ-10 Spin Column Plasmid DNA- Minipreps Bio Basic kit (Canada) according to manufactures protocol.

\section{Confirmation of $P$. aeruginosa}

All isolates were confirmed as $P$. aeruginosa using specific primers and PCR as shown in Table 1.

Table 1. Primer targets, sequences and their product size for five ESBLS and virulenc genes among $P$. aeruginosa isolate.

\begin{tabular}{|c|c|c|c|c|}
\hline Target & Primer & Primer sequence ( $5^{\prime}$ to $\left.3^{\prime}\right)$ & Product size (bp) & Ref. \\
\hline Pseudomonas species & PA-GS-F PA-GS-R & $\begin{array}{l}\text { GACGGGTGAGTAATGCCTA } \\
\text { CACTGGTGTTCCTTCCTATA }\end{array}$ & 618 & 25 \\
\hline P. aeruginosa & PA-SS-F PA-SS-R & $\begin{array}{l}\text { GGGGGATCTTCGGACCTCA } \\
\text { TCCTTAGAGTGCCCACCCG }\end{array}$ & 956 & 25 \\
\hline blaCTX-M & CTX-M (F) CTX-M (R) & $\begin{array}{l}\text { CGCTTTGCGATGTGCAG } \\
\text { ACCGCGATATCGTTGGT }\end{array}$ & 550 & 26 \\
\hline blaVEB-1 & VEB-1 (F) VEB-1 (R) & $\begin{array}{l}\text { CGACTTCCATTTCCCGATGC } \\
\text { GGACTCTGCAACAAATACGC }\end{array}$ & 642 & 27 \\
\hline blalMP & IMP-A IMB-B & $\begin{array}{l}\text { GAAGGCGTTTATGTTCATAC } \\
\text { GTACGTTTCAAGAGTGATGC }\end{array}$ & 587 & 28 \\
\hline blaVIM & VIM2004A VIM2004B & $\begin{array}{l}\text { GTTTGGTCGCATATCGCAAC } \\
\text { AATGCGCAGCACCAGGATAG }\end{array}$ & 382 & 28 \\
\hline blaSHV-1 & SHV-1 (F) SHV-1 (R) & $\begin{array}{l}\text { TGGTTATGCGTTATATTCGCC } \\
\text { GCTTAGCGTTGCCAGTGCT }\end{array}$ & 867 & 29 \\
\hline blaGES-1 & GES-1 (F) GES-1 (R) & $\begin{array}{l}\text { ATGCGCTTCATTCACGCAC } \\
\text { CTATTTGTCCGTGCTCAGG }\end{array}$ & 864 & 30 \\
\hline blaKPC & $K P C(F) K P C(R)$ & $\begin{array}{l}\text { ATGTCACTGTATCGCCGTCT } \\
\text { TTACTGCCCGTTGACGCCC }\end{array}$ & 880 & 31 \\
\hline blaOXA-50 & OXA- (F) OXA- (R) & $\begin{array}{l}\text { GAAAGGCACCTTCGTCCTCTAC } \\
\text { CAGAAAGTGGGTCTGTTCCATC }\end{array}$ & 400 & 32 \\
\hline blaNDM-1 & NDM-1 (F) NDM-1 (R) & $\begin{array}{l}\text { GGTGCATGCCCGGTGAAATC } \\
\text { GAGCACTTCTTTTGTGATGGC }\end{array}$ & 660 & 33 \\
\hline Tox A & Tox A-F Tox A-R & $\begin{array}{l}\text { CTGCGCGGGTCTATGTGCC } \\
\text { GATGCTGGACGGGTCGAG }\end{array}$ & 270 & 34 \\
\hline Las B & Las B-F Las B-R & $\begin{array}{l}\text { GGAATGAACGAAGCGTTCTCCGAC } \\
\text { TTGGCGTCGACGAACACCTCG }\end{array}$ & 284 & 34 \\
\hline Alg D & Alg D-F Alg D-R & $\begin{array}{l}\text { CGTCTGCCGCGAGATCGGCT } \\
\text { GACCTCGACGGTCTTGCGGA }\end{array}$ & 313 & 34 \\
\hline Exo $S$ & ExoS-F ExoS-R & $\begin{array}{l}\text { CTTGAAGGGACTCGACAAGG } \\
\text { TTCAGGTCCGCG TAGTGAAT }\end{array}$ & 504 & 15 \\
\hline ExoU & ExoU-F ExoU-R & $\begin{array}{l}\text { GGGAATACTTTCCGGGAAGTT } \\
\text { CGATCTCGCTGCTAATGTGTT }\end{array}$ & 428 & 15 \\
\hline PilB & PilB-F PilB-R & $\begin{array}{c}\text { ATGAACGACAGCATCCAACT } \\
\text { GGGTGTT GACGCGAAAGTCGAT }\end{array}$ & 826 & 15 \\
\hline
\end{tabular}




\section{Detection of ESBLs, MBLs and virulenc genes}

All primers, sequences and their product size for detection of extended-spectrum- $\beta$-lactamases (ES$B L s)$, metallo- $\beta$-lactamases (MBLs) and virulenc genes were used according to references (25-34) as shown in Table 1.

\section{Statistical analysis}

Data generated from the study were tabulated as Microsoft Excel sheet and Uploaded to Statistical Package for Social Sciences (SPPSS version 20), frequency and percentage were calculated for the categorical data and Pearson's chi-squared test or Fisher's exact test were applied to determine potential factors associated with $P$. aeruginosa and to determine whether there are any statistical differences between groups, the level of significance was set at a P value of 0.05 to test the hypothesis of no association. Fisher's exact test replaces chisquared test when the minimum expected count is less than five.

\section{Results}

General demographic characteristics of all 302 examined infants which were divided in hospitalized and non-hospitalized infants are shown in Table 2. A total of $16 / 302$ (5.3\%) isolates were found to be positive for $P$. aeruginosa (Table 2 ). All positive $P$. aeruginosa isolates were found in hospitalized infants. The age range of the enrolled hospitalized infants being colonized with $P$. aeruginosa was (127) days, about 10 (62.5\%) positive colonization occurred in females $(P=0.026)$ which is significant, positive colonization with

$P$. aeruginosa during the length of hospital stay had been taken into account, the mean length of hospital stay was 8.1 days (Table 2 ). All $P$. aeruginosa isolates were resistant to ciprofloxacin, norfloxacin and imipenem (25\%), followed by azetreonam (31\%), meropenem (38\%) piperacillin-tazobactam (44\%9, ceftazidime and amikacin (56\%) and gen- tamicin (75\%) (Table 3). The Minimum Inhibitory Concentration (MIC) range for four antibiotics are shown in Table 3, and none of the isolate was resistant to colistin.

The majority of fecal $P$. aeruginosa isolates were positive for the following virulence factors: ElastaseB (100\%) and AlgD (87.5\%), and slightly in less percentage $(81.3 \%)$ for both extracellular protein toxins (exoenzymes and exotoxinA) (Table 4). Both ExoenymeU and PilB protein were only positive in $61.3 \%$ and $6.3 \%$, respectiviely. All 16 isolates showed pigmentation of pyoverdin $(57.3 \%)$ or pyocyanin (42.7\%) and all produced beta-hemolysis on human and sheep blood in vitro (Table 5). Among the ESBLs, TEM was the most frequent enzyme found in $(81 \%)$ in $P$. aeruginosa isolates, followed by CTX-M (75\%), whereas the other types of VEB and GES were detected in the range of $6 \%$ and $13 \%$, respectively. Both blaOXA-50 and KPC were found at $81 \%$ and $69 \%$, respectively (Table 6).

Table 2. Major demographic characteristics of 302 investigated infants.

\begin{tabular}{|c|c|c|c|c|c|}
\hline \multirow[t]{2}{*}{$\begin{array}{c}\text { Patients } \\
\text { characteristics }\end{array}$} & \multicolumn{2}{|c|}{$\begin{array}{l}\text { hospitalized } \\
\text { infants }\end{array}$} & \multicolumn{2}{|c|}{$\begin{array}{c}\text { Non } \\
\text {-hospitalized } \\
\text { infants }\end{array}$} & \multirow[t]{2}{*}{ P-Value } \\
\hline & $n$ & $\%$ & $n$ & $\%$ & \\
\hline \multicolumn{6}{|l|}{ Gender } \\
\hline Males & 104 & 60 & 66 & 51.1 & \multirow{3}{*}{0.006} \\
\hline Females & 69 & 40 & 63 & 48.9 & \\
\hline Total & 173 & 57.3 & 129 & 42.7 & \\
\hline \multicolumn{6}{|l|}{ Age } \\
\hline 1-29 days & 170 & 98.3 & 43 & 33.3 & \multirow{2}{*}{$<0.001$} \\
\hline $1-12$ months & 3 & 1.7 & 86 & 66.7 & \\
\hline \multicolumn{6}{|l|}{ Clinical situation } \\
\hline $\begin{array}{l}\text { Presence of } \\
\text { diarrhea }\end{array}$ & \multicolumn{2}{|c|}{0} & 37 & 28.7 & $<0.001$ \\
\hline \multicolumn{6}{|c|}{ Prior use of Antibiotics } \\
\hline $\begin{array}{l}\text { Treatment with } \\
\text { Antibiotics }\end{array}$ & 61 & 35.3 & 34 & 26.4 & \multirow{2}{*}{0.049} \\
\hline $\begin{array}{l}\text { No antibiotics } \\
\text { treatment }\end{array}$ & 112 & 64.7 & 95 & 73.6 & \\
\hline
\end{tabular}


Table 3. Antimicrobial susceptibility pattern of 16 $P$. aeruginosa isolates using diffusion disc amd MIC-Etest mehods.

\begin{tabular}{|c|c|c|c|c|c|}
\hline \multirow[t]{2}{*}{ Domains/Facets } & \multicolumn{2}{|c|}{ Resistant } & \multirow{2}{*}{\begin{tabular}{|l|} 
MIC50 \\
$\mu \mathrm{g} / \mathrm{ml}$
\end{tabular}} & \multirow{2}{*}{\begin{tabular}{|l} 
MIC90 \\
$\mu \mathrm{g} / \mathrm{ml}$
\end{tabular}} & \multirow{2}{*}{$\begin{array}{c}\text { MIC } \\
\text { Range } \\
\mu g / \mathrm{ml}^{*}\end{array}$} \\
\hline & No. & $\%$ & & & \\
\hline Ciprofloxacin & 4 & 25 & - & - & - \\
\hline Imipenem & 4 & 25 & 3.6 & 6.5 & $0.75-32$ \\
\hline Aztreonam & 5 & 31 & - & - & - \\
\hline Meropenem & 6 & 38 & - & - & - \\
\hline $\begin{array}{l}\text { Piperacillin- } \\
\text { tazobactam }\end{array}$ & 7 & 44 & - & - & - \\
\hline Ceftazidime & 9 & 56 & 1.92 & 3.45 & $0.50-12^{* *}$ \\
\hline Amikacin & 9 & 56 & 7.62 & 13.72 & $3-48$ \\
\hline Gentamicin & 12 & 75 & - & - & - \\
\hline Colistin & - & & 0.18 & 0.32 & $0.50-1.2$ \\
\hline \multicolumn{6}{|c|}{$\begin{array}{r}* \text { : Breakpoints for susceptible P. aeruginosa isolates }(\mu \mathrm{g} / \mathrm{ml}) \\
\text { were the following: Amikacin; } \leq 8 \text {, Ceftazidime; } \\
\leq 8, \text { Imipenem } \leq 4 \text {, Colistin; } \leq 2 . \\
* * \text { : Only } 25 \% \text { of isolates were resistant using Etest. }\end{array}$} \\
\hline
\end{tabular}

Table 4. Distribution of virulence genes among 16 $P$. aeruginosa isolates.

\begin{tabular}{|l|c|c|c|}
\hline \multirow{2}{*}{ Virulence factor } & Gene & \multicolumn{2}{c|}{ No. (\%) Positive } \\
\cline { 3 - 4 } & & \multicolumn{2}{c|}{ virulence genes } \\
\hline Elastase B & las B & 16 & $(100)$ \\
\hline Alginate & alg D & 14 & $(87.5)$ \\
\hline Exotoxin A & tox A & 13 & $(81.3)$ \\
\hline Exoenyme S & exo S & 13 & $(81.3)$ \\
\hline Exoenyme U & exo U & 5 & $(31.3)$ \\
\hline PilBprotein & pil B & 1 & $(6.3)$ \\
\hline Pyoverdin* & - & 9 & $(57.3)$ \\
\hline Pyocyanin* & - & 7 & $(42.7)$ \\
\hline Beta-hemolysis** & - & 16 & $(100)$ \\
\hline
\end{tabular}

*: Recorded by presence the yellow-green color (pyoverdin) or blue-green color (pyocyanin) of isolates on Pseudomonas culture agar after 24-48 hr incubation $\star \star$ : Detected by presence of complete hemolytic activity of isolat es on human and sheep blood agar plates after $48 \mathrm{hr}$ incubation
Table 5. Distribution of ESBLs genes among $16 P$. aeruginosa isolates.

\begin{tabular}{|l|c|c|}
\hline \multirow{2}{*}{ Virulence factor } & \multicolumn{2}{c|}{$\boldsymbol{P}$. aeruginosa isolates } \\
\hline blaTEM & No. & $\%$ \\
\hline blaCTX-M & 13 & 81 \\
\hline blaSHV-1 & 12 & 75 \\
blaGES-1 & 10 & 63 \\
blaVEB & 2 & 13 \\
\hline blaKPC & 1 & 6 \\
\hline blaOXA-50 & 11 & 69 \\
blaVIM & 13 & 81 \\
blaIMP & 12 & 75 \\
blaNDM-1 & \multicolumn{2}{|}{ Nil } \\
\hline
\end{tabular}

\section{Discussion}

Pseudomonas aeruginosa is accounting for $7.1 \%$ of all hospital infections in the United States according to a recent study [35]. The organism is a frequent colonizer of intestinal tract of human, especially after prolonged antibiotic treatment or ICUs admission. Since $P$. aeruginosa is widely distributed in most hospital settings, the organism is often colonizing and infect hospitalized patients, particularly immune-compromised patients, patients with compromised lungs and burns as well as infants in neonatal intensive care units (NICU) [36, 39-40]. Previous studies have demonstrated that colonization of adults and children patients with $P$. aeruginosa can be associated with diarrhea or subsequent infection with the same strain of $P$. aeruginosa [36, 39-40]. Therefore, detection of patients in the ICUs colonized with $P$. aeruginosa can be helpful to control hospital acquired infection and in selection of empiric antibiotics in suspected cases of sepsis [36].

The present study shows that $5.3 \%$ of $P$. aeruginosa isolates were recovered from the fecal samples of hospitalized infants in (NICU), whereas all fecal samples obtained from non-hospitalized pa- 
tients were negative. The majority of these isolates (62.5\%) was significantly found $(P=0.006)$ in feces of hospitalized femal infant as shown in Table $\mathbf{2}$.

Recent studies reported that nosocomial outbreaks caused by MDR $P$. aeruginosa are occurring around the world, and these outbreaks are frequently caused by clones of

$P$. aeruginosa producing metallo-betalctamases (MBLs), mostly VIM and IMP types. These resistance markers can be acquired either by chromosomal mutations or horizontal gene transfer [41-42]. Neonatal infection with $P$. aeruginosa is mostly acquired due to their underdeveloped immune system, especially when these infants are catheterized with intravascular catheters/devices and/or receiving parenteral nutrition, [43-44]. Almost all P. aeruginosa isolates in this study were resistant for one or more commonly used antibiotics in treatment of Pseudomonas infections, especially to carbapenems (meropenem and impenem) (Table 3). This can be explained by the overexpression of efflux pumps that expel carbapenems and lead to carbapenem resistance [45]. However, all isolates were susceptible to colistin.

The present study demonstrates that both OXA50 and TEM were the most frequent phenotypes found in $P$. aeruginosa isolates, followed by CTX-M, BlaVIM-2, whereas both blaIMP-15 and blaNDM-1 were not detected in all isolates. These findings are in agreement with a recent published study on $P$. aeruginosa isolates from respiratory tract of Jordanian patients [5].

The present study has detected that high percentage of our $P$. aeruginosa isolates (68.7\%) were producers of KPC. This result should be considered serious since $K P C$ genes found often in association with transferable plasmids and transposons, and can result in a rapid spread of these genes in Gram-negative opportunistic pathogens [46-47]. However, it is important to note that NDM-1 type carbapenemase is not detected in any of the

\section{$\boldsymbol{P}$. aeruginosa isolates}

The majority of our fecal $P$. aeruginosa isolates were positive for some of the most important virulence factors as presented by ElastaseB and AlgD, and slightly in less rate for both extracellular protein toxins, Exoenzymes and ExotoxinA. A previous Jordanian study has also shown that $P$. aeruginosa isolates from respiratory tract sources were mostly producers of same virulence factors [5].

The majority of our $P$. aeruginosa isolates produced pigments, either pyoverdin or pyocyanin. The redox-active pigment pyocyanin is responsible for the blue-green color characteristics of $P$. aeruginosa, and it is also required to express cell fatal cytotoxicity, while pyoverdine is a siderophore involved in iron acquisition, participate in biofilm formation, and its chelating activity may contribute in developing antibiotics resistance [13, 19].

\section{Conclusion}

This study provides important epidemiological data on antimicrobial resistance profiles, distribution of ESBLS and MBLs and presence of virulence factors among fecal $P$. aeruginosa isolates from infants during their hospitalized.

\section{References}

1. Walkty A., Lagace-Wiens P, Adam H., Baxter M., Karlowsky J., Mulvey MR., Zhanel GG. Antimicrobial susceptibility of 2906 Pseudomonas aeruginosa clinical isolates obtained from patients in Canadian hospitals over a period of 8 years: Results of the Canadian Ward surveillance study (CANWARD), 2008. Diag Microbiol Infect Dis 2017;87 (1):60-63.

2. Chatterjee $M$, Anju CP, Biswas L, Kumar VA, Mohan CG, Biswas R. Antibiotic resistance in Pseudomonas aeruginosa and alternative therapeutic options. Int J Med Microbiol2016;306 (1):48-58

3. Nguyen L, Garcia J, Gruenberg K, MacDougall C. Multidrug Resistant Pseudomonas Infections: Hard to Treat, But Hope on the Horizon? Curr Infect Dis Rep. 2018;6;20 (8):23. 
4. Koutsogiannou M, Drougka $E$, Liakopoulos $A$, Jelastopulu $E$, Petinaki E, Anastassiou ED, et al. Spread of Multidrug-Resistant Pseudomonas aeruginosa Clones in a University Hospital. J Clin Microbiol 2013;51 (2):665-668.

5. Al Dawodeyah HY, Nathir Obeidat N, Abu-Qatouseh LF, Shehabi A A. Antimicrobial resistance and putative virulence genes of Pseudomonas aeruginosa isolates from patients with respiratory tract infection. Germs 2018;8 (1):31-40.

6. Hashem H, Hanora A, Abdalla S, Shawky A, Saad A. Carbapenem Susceptibility and Multidrug-Resistance in Pseudomonas aeruginosa Isolates in Egypt. Jundishapur J Microbiol 2016;9 (11).

7. Hong DJ., Bae IK, Jang IH, Jeong SH, Kang, HK, Lee $K$. Epidemiology and characteristics of metallo- $\beta$-lactamaseproducing Pseudomonas aeruginosa. Infect Chemother 2015;47 (2):81-97.

8. Gupta V, Datta P, and Chander J. Prevalence of metallo beta lactamase (MBL) producing Pseudomonas spp. and Acinetobacter spp. in a tertiary care hospital in India. J Infect 2006;52:311-314.

9. Breidenstein EB, de la Fuente-Núñez C, Hancock RE. Pseudomonas aeruginosa: all roads lead to resistance. Trends Microbiol 2011;19 (8):419-426.

10. Lister PD, Wolter DJ, Hanson ND. Antibacterial-resistant Pseudomonas aeruginosa: clinical impact and complex regulation of chromosomally encoded resistance mechanisms. Clin Microbiol Rev 2009;22 (4):582-610.

11. Shehabi AA, Masoud H, Balkam Maslamani FA. Common Antimicrobial Resistance Pattern, Biotypes and Serotypes Found among Pseudomonas aeruginosa Isolates from Patient's Stools and Drinking Water Sources in Jordan. J Chemother 2005;17 (2):179-183

12. Rosenthal VD, Al-Abdely HM, El-Kholy AA, AlKhawaja SAA, Leblebicioglu $\mathrm{H}$, Mehta $\mathrm{Y}$, et al. International Nosocomial Infection Control Consortium report, data summary of 50 countries for 2010-2015: Device-associated module. Am J Infect Control 2016;44 (12):1495-1504.

13. Lau GW, Hassett DJ, Britigan BE. Modulation of lung epithelial functions by Pseudomonas aeruginosa. Trends in microbiology 2005; 13 (8): 389-397.

14. Dénervaud V1, TuQuoc $P$, Blanc D, Favre-Bonté $S$, Krishnapillai $V$, Reimmann C. Characterization of cell-to-cell signaling-deficient Pseudomonas aeruginosa strains colonizing intubated patients. J Clin Microbiol. 2004;42 (2):554-62.

15. Mitov I, Strateva T, Markova B. Prevalence of virulence genes among Bulgarian nosocomial and cystic fibrosis isolates of Pseudomonas aeruginosa. Braz J Microbiol 2010;41 (3):588595.

16. Hauser AR, Jain, M Bar-Meir M, McColley SA. Clinical significance of microbial infection and adaptation in cystic fibrosis. Clin Microbial Rev 2011;24 (1):29-70.
17. Shaikh S, Fatima J, Shakil S, Rizvi S MD, Kamal MA. Antibiotic resistance and extended spectrum beta-lactamases: Types, epidemiology and treatment. Saudi J Biol Sci 2015;22 (1):90101.

18. Gonc alves IR. Cavalcanti Dantas RC, Ferreira M L, da Fonseca Batistão DW, Gontijo-Filho PP, Ribas RM . Carbapenem-resistant Pseudomonas aeruginosa: association with virulence genes and biofilm formation. Braz J Microbiol 2017;48:211-217.

19. Shehabi AA and Kamal MA. Pseudomonas aeruginosa, a common opportunistic pathogen in Jordan: A short review article. IAJAA 2019; 9:1, 1.

20. Mahfoud M, Al Najjar M, Hamzeh AR. Multidrug resistance in Pseudomonas aeruginosa isolated from nosocomial respiratory and urinary infections in Aleppo, Syria. J Infect Develop Count 2018; 9 (2):210-3.

21. Hayajneh WA, Hajj A, Hulliel F, Sarkis DK, Irani-Hakimeh N, Kazan $L$, et al. Susceptibility trends and molecular characterization of Gram-negative bacilli associated with urinary tract and intraabdominal infections in Jordan and Lebanon: SMART 20112013. Int J Infect Dis 2015;35:56-61.

22. Al Bayssari C, Diene SM, Loucif L, Gupta SK, Dabboussi F, et al. Emergence of VIM-2 and IMP-15 Carbapenemases and Inactivation of OprD Gene in Carbapenem-Resistant Pseudomonas aeruginosa Clinical Isolates from Lebanon. Antimicrob Agents Chemother 2014;58 (8):4966-4970.

23. Mansour SA, Eldaly O, Jiman-Fatani A, Mohamed ML, Ibrahim EM. Epidemiological characterization of P. aeruginosa isolates of intensive care units in Egypt and Saudi Arabia. East Mediterr Health J 2013;19:71-80.

24. Clinical Laboratory and Standards Institute (CLSI). Methods for dilution antimicrobial susceptibility tests for bacteria that grow aerobically; approved standard - tenth edition. CLSI document M07-A10 Villanova, PA, USA: CLSI, 2015.

25. Spilker T, Coenye T, Vandamme P, LiPuma JJ. PCR-based assay for differentiation of Pseudomonas aeruginosa from other Pseudomonas species recovered from cystic fibrosis patients. J Clini Microbial 2004;42 (5):2074-2079.

26. Bokaeian M, Shahraki Zahedani S, Soltanian Bajgiran M, Ansari Moghaddam A. Frequency of PER, VEB, SHV, TEM and CTX-M genes in resistant strains of Pseudomonas aeruginosa producing extended spectrum $\beta$-lactamases. Jundishapur J Microbiol 2014;8: e13783

27. Jiang $X, N i$, Jiang $Y$, Yuan $F$, Han $L$, Li $M$, et al. Outbreak of infection caused by Enterobacter cloacae producing the novel VEB-3 beta-lactamase in China. J Clin Microbiol 2000;43 (2):826-31.

28. Hemalatha V, Sekar U, Kamat V. Detection of metallo betalactamase producing Pseudomonas aeruginosa in hospitalized patients. Indian J Med Res 2005;122 (2):148. 
29. Fazeli N, Momtaz H. Virulence gene profiles of multidrugresistant Pseudomonas aeruginosa isolated from Iranian hospital infections. Iran Red Crescent Med J. 2014;18; 16 (12).

30. Polotto M1, Casella T, de Lucca Oliveira MG, Rúbio FG, Nogueira $M L$, de Almeida MT, et al. Detection of $P$. aeruginosa harboring bla CTX-M-2, bla GES-1 and bla GES-5, bla IMP-1 and bla SPM-1 causing infections in Brazilian tertiary-care hospital. BMC Infect Dis. 2012;3 (12):176.

31. Akpaka PE, Swanston WH, Ihemere HN, Ihemere NH, Correa A, Torres A J. et al. Emergence of KPC-producing Pseudomonas aeruginosa in Trinidad and Tobago. J Clin Microbiol 2009;47 (8):2670-1.

32. Girlich D, Naas T, Nordmann P. Biochemical Characterization of the Naturally Occurring Oxacillinase OXA-50 of Pseudomonas aeruginosa. Antimicrobial Agent Chempther 2004;48:20432048.

33. Bonnin RA, Naas T, Poirel L, Nordmann, P. Phenotypic, biochemical, and molecular techniques for detection of metallo$\beta$-lactamase NDM in Acinetobacter baumannii. J Clin Microbiol 2012;50 (4):1419-1421.

34. Wolska K, Szweda P. Genetic features of clinical Pseudomonas aeruginosa strains. Pol J Microbiol 2009;58:255-60.

35. Magill SS, Edwards JR, Bamberg W, Beldavs ZG., Dumyati G, Kainer MA, et al. Multistate point-prevalence survey of health care-associated infections. New Eng J Med 2014;370 (13):11981208.

36. Harris AD, Jackson SS, Robinson G, Pineles L, Leekha S, Thom $K A$, et al. Pseudomonas aeruginosa colonization in the intensive care unit: prevalence, risk factors, and clinical outcomes. Infect Control Hosp Epidemiol 2016;37 (5):544-548.

37. Jefferies JMC, Cooper T, Yam T, Clarke SC. Pseudomonas aeruginosa outbreaks in the neonatal intensive care unit-a systematic review of risk factors and environmental sources. J Med Microbiol 2012;61 (8):1052-1061.

38. Modi SR, Collins JJ, Relman DA. Antibiotics and the gut microbiota. J Clinical Invest 2014;124 (10):4212.

39. Chuang $\mathrm{CH}$, Janapatla RP, Wang YH, Chang HJ, Huang YC, Lin TY, et al. Pseudomonas aeruginosa-Associated Diarrheal Diseases in Children. Pediatr Infect Dis J 2017;36 (12):1119-1123..

40. Nesher L, Rolston KVI, Shah DP, Tarrand JT, Mulanovich $V$, Ariza-Heredia EJ, et al. Fecal colonization and infection with Pseudomonas aeruginosa in recipients of allogeneic hematopoietic stem cell transplantation. Transpl Infect Dis 2015;17 (1):33-38.

41. Ozsurekci $Y$, Aykac K, Cengiz AB, Basaranoglu ST, Sancak $B$, Karahan S, et al. Bloodstream infections in children caused by carbapenem-resistant versus carbapenem-susceptible gramnegative microorganisms: Risk factors and outcome. Diagn Microbiol Infect Dis 2017;87 (4):359-364.
42. Al Bayssari C, Diene SM, Loucif L, Gupta SK., Dabboussi F, Mallat $\mathrm{H}$, Emergence of VIM-2 and IMP-15 carbapenemases and inactivation of oprD gene in carbapenem-resistant Pseudomonas aeruginosa clinical isolates from Lebanon. Antimicrob Agents Chemother 2014;58 (8): 4966-4970.

43. Folgori L, Bielicki J, Heath PT, Sharland M. Antimicrobial-resistant Gram-negative infections in neonates: burden of disease and challenges in treatment. Curr Opin Infect Dis 2017;30 (3): 281288.

44. Pepin CS, Thom KA, Sorkin JD, Leekha S, Masnick M, Preas $M A$, et al. Risk Factors for Central-Line-Associated Bloodstream Infections: A Focus on Comorbid Conditions. Infect control Hosp epidemiol 2015;36 (4):479-481.

45. Meletis G. Carbapenem resistance: overview of the problem and future perspectives. Ther Adv Infect Dis 2016;3 (1):15-21.

46. Rizek C, Fu L, dos Santos LC, Leite G, Ramos J, Rossi F, et al. Characterization of carbapenem-resistant Pseudomonas aeruginosa clinical isolates, carrying multiple genes coding for this antibiotic resistance. Ann Clin Microbiol Antimicrob 2014;2:13:43

47. Vanegas JM, Cienfuegos AV, Ocampo AM, López L, del Corral $H$, Roncancio, $G$, et al. Similar frequencies of Pseudomonas aeruginosa isolates producing KPC and VIM carbapenemases in diverse genetic clones at tertiary-care hospitals in Medellin, Colombia. J Clin Microbiol 2014;52 (11):3978-3986

\section{Publish in The International}

Arabic Journal of Antimicrobial Agents

The Journal is an open access peer-reviewed journal that publishes scientific papers about all aspects of antimicrobials. The journal will publish original research articles, reviews, brief reports and case reports dealing with basic and clinical antibacterial agents, antiviral, antiprotozoals, antituberculuous, antifungal and antihelminthes agents. All manuscripts must be prepared in English, and are subject to a rigorous and fair peer-review process. Accepted papers will immediately appear online. The journal aims to advance the knowledge, attitude and the research of chemotherapy in the Arabic world in cooperation with international, national scientific and public societies as well as research centers with similar aims and objectives. 